\title{
Long-term prognosis of geriatric major depression in relation to cognition and white matter integrity: follow up of two cases
}

Prognóstico de longo prazo da depressão geriátrica em relação à cognição e à integridade da substância branca: acompanhamento de dois casos

Carlos Eduardo de Oliveira Alves', Gilberto Sousa Alves', Felipe Kenji Sudo', Maria Elisa Lanna², Letice Ericeira-Valente', Denise Madeira Moreira ${ }^{3}$, Jerson Laks', Eliasz Engelhardt²

\begin{abstract}
Introduction: The geriatric depression (GD) represents one of the most frequent psychiatric disorders in outpatient services specialized in old-age treatment. Objective: The course of two illustrative cases of GD is discussed, highlighting its clinical picture after antidepressant treatment and underlining variables related to disease prognosis, treatment effectiveness and conversion to major cognitive disorders such as vascular dementia (VD). Methods: The cognitive performance, depressive symptoms, autonomy and brain structural measurements as white matter hyperintensities (WMH) and hippocampal size, and microstructural integrity of WM with diffusion tensor imaging were followed during four years. Results: Case 1, with a severe degree of $\mathrm{WMH}$, was associated with worsening cognition and increasing functional disability. Case 2, with mild WMH, an improvement of cognitive functioning could be seen. Conclusions: The existence of different subtypes of GD, as presented in this report, points a pathophysiological heterogeneity of GD, and suggests a possible continuum vascular depression ( $\mathrm{VaDp}$ ) and vascular cognitive impairment (VCI).
\end{abstract}

\section{RESUMO}

Introdução: A depressão geriátrica (DG) representa um dos mais frequentes transtornos psiquiátricos em ambulatórios especializados em idosos. Objetivo: Discutir a evolução da DG por meio de dois casos ilustrativos, destacando-se as variáveis relacionadas ao prognóstico da doença e à conversão para quadros cognitivos mais graves como demência vascular (DV). Métodos: Os casos foram acompanhados por quatro anos com medidas do desempenho cognitivo, funcional, sintomas depressivos, juntamente com as alterações de estruturas cerebrais, como hiperintensidades da substância branca (HSB), dimensões hipocampais, e a integridade microestrutural da SB, por meio de imagens com tensor de difusão. Resultados: Caso 1, com grave intensidade de HSB, evoluiu com piora cognitiva e funcional. Caso 2, com leve intensidade de HSB, evoluiu com melhora cognitiva após o tratamento da depressão. Conclusões: A existência de diferentes subtipos de DG, como apresentado neste relato, aponta para a heterogeneidade da fisiopatologia da DG, sugerindo um possível continuum entre depressão vascular (DpVa) e comprometimento cognitivo vascular (CCV).

1 Federal University of Rio de Janeiro (UFRJ), Psychiatry Institute (CDA/PUB), Center for Alzheimer's Disease and Related Disorders. 2 UFRJ, INDC-CDA/IPUB, Cognitive and Behavioral Unit. 


\section{INTRODUCTION}

Late-life depression or geriatric depression (GD) represents one of the most frequent psychiatric disorders in specialized outpatient services ${ }^{1}$ and affects nearly $9 \%$ to $18 \%$ of the general elderly ${ }^{2,3}$. GD may affect from $3.2 \%$ to $15.4 \%$ of the elderly Brazilian population ${ }^{4,5}$.

The course of GD has shown to be rather heterogeneous $^{6}$, and it is assumed that the combination of white matter lesions and cognitive symptoms related to frontal lobe dysfunction might be associated to GD with specific features. This led to the concept of Vascular Depression (VaDp) hypothesis?. This condition proposed by Alexopoulos includes major depression occurring after 65 years of age, vascular risk factors and significant cerebrovascular disease, as main aspects, and cognitive impairment, represented by executive dysfunction, as a secondary aspect ${ }^{7}$. In some situations a spectrum of cognitive and behavioral impairment of vascular etiology, comprising vascular depression (VaDp), mild vascular cognitive impairment (VMCI), and vascular dementia ( $\mathrm{VaD}$ ) may be considered ${ }^{8,9}$.

The affective symptoms and executive dysfunction are both related to disconnection of prefrontal-subcortical circuits $^{10}$. Different frontal connections, such as the cortico-limbic-striatum-pallidum-thalamic-cortical circuits, have been shown to play an important role in affective modulation ${ }^{11,12}$, contributing to the pathogenesis of some cases of late-life depression ${ }^{13}$. Noteworthy, frontal vascular lesions have shown to be associated with a poorer response to antidepressant treatment ${ }^{14}$.

MR studies with diffusion tensor (DTI) acquisitions and fractional anisotropy (DTI-FA) are used to evaluate white matter integrity in psychiatric illness, such as depression ${ }^{15}$.

This study aims to examine the heterogeneity of outcome patterns of GD. Two cases of depression, with behavioral, neuropsychological, and neuroimaging assessments followed up for four years are described as examples. The hypothesis of a continuum between $\mathrm{VaDp}$ and $\mathrm{VCl}$ (which includes $\mathrm{VMCl}$ and $\mathrm{VaD}$ ) is analyzed, as well as the association between brain vascular lesions in specific regions and poor response to antidepressant treatment.

\section{METHODS}

Two cases of GD were assessed over a 4-year-period at the specialized geriatric outpatient unit (Centre for Alzheimer Disease and Related Disorders) of the Federal University of Rio de Janeiro (CDA/IPUB-UFRJ-Brazil).

The cases fulfilled Alexopoulous' criteria for vascular depression ${ }^{7}$. Hamilton Depression Scale ${ }^{16}$ was applied to investigate depressive symptoms and the Neuropsychiatric Inventory (NPI) for a global evaluation of behavioral disturbances ${ }^{17}$.
Cognitive, functional, and behavioral performance and staging were assessed, as well as neuroimaging, according to the protocol of vascular dementia $(\mathrm{VaD})$ recommendations of the DNCE-ABN which include the Mini-Mental State Examination (MMSE), a validated Brazilian version of CAMCOG, executive function assessment (Trail-Making Test - TMT), Clock Drawing Executive Task - CLOX, and semantic verbal fluency - VF [category animals]). TMT A can be considered as an indicator of visual-motor speed (processing speed), and TMT B can be considered as an indicator of cognitive flexibility. CDR scale was used for staging of dementia Functional Activities Questionnaire (FAQ) was applied to evaluate instrumental activities of daily-living (IADLs). The Hachinski Ischemic Score (EIH) for stroke risk assessment was used. The evaluation of the severity of white matter hyperintensities (WMH) was performed with a modified Fazekas scale (mFazekas). De Leon score was applied to evaluate hippocampal atrophy ${ }^{18}$.

The neuroimaging evaluation was performed with MRI of the brain at baseline and at the end of the follow up (over three years later) with a GE Signa Horizon (1.5 T) equipment for standard acquisitions (including FLAIR sequence), and diffusion tensor imaging (DTI), for fractional anisotropy measurements (DTI-FA). Post-processing of DTI was performed at a ADW 4.3 workstation with Functool 4.5.3 (GE Medical Systems) to obtain the quantitative values of DTI-FA.

\section{RESULTS}

The case 1 relates to a 73 years old, female with seven year of schooling who suffered from hypertension and diabetes mellitus. She reported that two years earlier she experienced her first episode of depression, which caused a negative effect on her capacity to look after herself, pessimism, sadness, and increased dependency of her daily life activities. At that time, Sertraline $50 \mathrm{mg}$ was introduced, with good clinical response.

At the initial consultation at this clinic, she presented memory complaints. The neuropsychological assessment revealed impairment of cognitive performance, with low global CAMCOG and attention and abstract thinking subscales, and the tests for executive function, TMT and CLOX, suggested impairment of executive function. CDR was 0.5 (Table 1). MRI showed moderate intensity of WMH (mFazekas score $=2$ ) (Figure 1A). De Leon score for hippocampus was within normal values (Table 2 ).

Over the four-year period the patient presented several episodes of depression, and progression of cognitive impairment, mainly of executive function. Sertraline was increased up to $200 \mathrm{mg} /$ day for treatment of the relapse of depressive symptoms in the first six months. At the $6^{\text {th }}$ month evaluation, the patient still showed intense depressive symptoms, 
together with difficulty in dealing with daily-life activities, such as controlling her own medication, preparing meals, keeping up to date with community life $(F A Q=13)$. Sertraline was substituted for Venlafaxine, $150 \mathrm{mg} /$ day, and by the end of the $1^{\text {st }}$ year, the affective symptoms showed remarkable improvement. The patient did not return to the clinic during the second year, continuing the treatment in a local health clinic. On returning to the clinic, she reported two new episodes of depression, partially controlled with Mirtazapine $45 \mathrm{mg}$ in association with Bupropion $150 \mathrm{mg}$. One year after her last evaluation, the patient showed a relapse of the depressive symptoms (Table 3). In the last year of the follow-up the patient's depressive symptoms showed improvement. However, global CAMCOG and memory subscale remained low, as well as executive function. CDR increased from 0.5 to 1 (Tables 1 and 3).

A new MRI showed an increase of white matter load ( $\mathrm{mFa-}$ zekas score $=3$ ) (Figure 1B), while there were no hippocampal changes in comparison to the initial findings (Table 2).
The comparative results of the DTI-FA are seen bellow.

The case 2 is about a 67 years old, female, with three years of schooling, who was hypertensive but not diabetic, whose first interview revealed severe late-life depressive symptoms, started one year before, when her son died. The global CAMCOG score was about average, with lower scores on attention and abstract thinking subscales, as well as low scores on TMT and CLOX, compatible with executive dysfunction. There was a mild functional decline. CDR was 0.5 (Table 1).

The initial MRI showed low level WMH (mFazekas score =1) (Figure 2A), while the hippocampal were in the normal range.

After being treated for depression with Sertraline, increased up to $100 \mathrm{mg}$, for one year, the depressive symptoms improved, accompanied by improvement in global CAMCOG and the subscales scores, as well as of executive function, and functional improvement. CDR was zero (Table 1). These improvements were sustained for the following 4 years (Table 1).

Table 1. Cognitive follow-up data

\begin{tabular}{|c|c|c|c|c|c|c|c|}
\hline & & \multicolumn{2}{|c|}{ Case 1} & \multicolumn{2}{|c|}{ Case 2} & \multicolumn{2}{|c|}{ Normative values $(*)$} \\
\hline & & BL & Year 4 & BL & Year 4 & Case 1 & Case 2 \\
\hline \multicolumn{2}{|c|}{$\begin{array}{l}\text { CAMGOG } \\
\text { global }\end{array}$} & 74 & 69 & 78 & 91 & $\begin{array}{l}83.52 \\
(7.23)\end{array}$ & $\begin{array}{l}76.11 \\
(7.36)\end{array}$ \\
\hline \multirow[t]{8}{*}{ CAMCOG subscales } & Orientation & 7 & 9 & 10 & 10 & $\begin{array}{l}9.37 \\
(0.81)\end{array}$ & $9.27(0.78)$ \\
\hline & Language & 23 & 23 & 27 & 28 & $\begin{array}{l}25.04 \\
(2.13)\end{array}$ & $\begin{array}{l}23.46 \\
(2.02)\end{array}$ \\
\hline & Memory & 18 & 15 & 19 & 19 & $\begin{array}{l}21.44 \\
(3.48)\end{array}$ & $\begin{array}{l}20.70 \\
(3.08)\end{array}$ \\
\hline & Praxis & 11 & 9 & 10 & 12 & $\begin{array}{c}9.78 \\
(1.55)\end{array}$ & $\begin{array}{c}9.42 \\
(1.63)\end{array}$ \\
\hline & Perception & 8 & 7 & 7 & 8 & $\begin{array}{c}6.96 \\
(1.36)\end{array}$ & $\begin{array}{c}5.86 \\
(1.38)\end{array}$ \\
\hline & Calculation & 2 & 2 & 2 & 2 & $\begin{array}{l}1.78 \\
(0,50)\end{array}$ & $1.65(0,48)$ \\
\hline & Attention & 3 & 3 & 3 & 7 & $\begin{array}{c}5.00 \\
(1,81)\end{array}$ & $4,27(1.76)$ \\
\hline & Abstract. Thinking & 2 & 4 & 0 & 5 & $\begin{array}{l}4.70 \\
(1.95)\end{array}$ & $\begin{array}{l}2.50 \\
(2.10)\end{array}$ \\
\hline \multirow{4}{*}{$\begin{array}{l}\text { Executive Function } \\
\text { Tests }\end{array}$} & Clox I/II & $11 / 15$ & $13 / 15$ & $9 / 15$ & $15 / 15$ & & \\
\hline & $\begin{array}{l}\text { TMT-A } \\
(\%)\end{array}$ & $\begin{array}{c}70 \\
(50 \%-75 \%)\end{array}$ & $\begin{array}{c}85 \\
(25 \%-50 \%)\end{array}$ & $\begin{array}{c}165 \\
(<10 \%)\end{array}$ & $\begin{array}{c}73 \\
(25 \%-50 \%)\end{array}$ & & \\
\hline & $\begin{array}{l}\text { TMT-B } \\
(\%)\end{array}$ & $\begin{array}{c}360 \\
(10 \%-25 \%)\end{array}$ & $\begin{array}{c}859 \\
(<10 \%)\end{array}$ & $\begin{array}{c}445 \\
(<10)\end{array}$ & $\begin{array}{c}225 \\
(10 \%-25 \%)\end{array}$ & & \\
\hline & TMT-B/TMT-A & 5.14 & 10.10 & 2.69 & 3.08 & & \\
\hline \multicolumn{2}{|c|}{ FAQ } & 0 & 4 & 3 & 0 & & \\
\hline \multicolumn{2}{|c|}{ CDR } & 0,5 & 1 & 0,5 & 0 & & \\
\hline
\end{tabular}


Table 2. Neuroimage data

\begin{tabular}{|c|c|c|c|c|c|}
\hline & & \multirow{2}{*}{$\begin{array}{l}\text { Hippocampus (I/r) } \\
\text { (de Leon et al., 1993) }\end{array}$} & \multirow{2}{*}{$\begin{array}{l}\text { WMH modified Fazekas } \\
\text { (Gouw et al., 2008) }\end{array}$} & \multicolumn{2}{|c|}{$\begin{array}{l}\text { DTI-FA } \\
\text { values }\end{array}$} \\
\hline & & & & Frontal & Posterior \\
\hline \multirow[t]{2}{*}{ Case 1} & Baseline & $1 / 3$ & 2 & 0.239 & 0.352 \\
\hline & Year 4 & $1 / 3$ & 3 & 0.258 & 0.296 \\
\hline \multirow[t]{2}{*}{ Case 2} & Baseline & $0 / 3$ & 1 & 0.315 & 0.347 \\
\hline & Year 4 & $0 / 3$ & 1 & 0.334 & 0.349 \\
\hline $\begin{array}{l}\text { Control values [-1dp] } \\
\text { [range] }\end{array}$ & & $0 / 3-1 / 3$ & $0-1$ & $\begin{array}{c}0.313 \pm 0.023 \\
{[-1 \mathrm{~d} p=0,290]} \\
{[0.284-0.351]}\end{array}$ & $\begin{array}{c}0.394 \pm 0.046 \\
{[-1 \mathrm{~d} p=0.348]} \\
{[0.316-0.457]}\end{array}$ \\
\hline
\end{tabular}

Table 3. Behavioral follow-up data

\begin{tabular}{lcccc}
\hline \multirow{2}{*}{ Year } & \multicolumn{2}{c}{ Case 1 } & \multicolumn{2}{c}{ Case2 } \\
\cline { 2 - 5 } & HAM-D & NPI & HAM-D & NPI \\
\hline BL & 5 & 8 & 20 & 14 \\
0.5 & 15 & 38 & 1 & 3 \\
1 & 2 & 9 & 5 & 6 \\
3 & 18 & 16 & 2 & 0 \\
4 & 7 & 28 & 1 & 0 \\
\hline
\end{tabular}

HAM-D: Hamilton Depression Scale; NPI: Neuropsychiatric Inventory; BL: baseline.

At the end of this study, the patient was again submitted to $\mathrm{MRI}$, which revealed a very slight increase of $\mathrm{WMH}$, maintaining the same score (mFazekas score $=1$ ) (Figure 2B), and no hippocampal changes were found (Table 2).

The comparative results of the DTI-FA are as follows.

\section{Results of DTI-FA}

The DTI data of both cases were submitted to post-processing to obtain DTI-FA values of the subcortical white matter, which were compared with a control sample of normal elderly individuals ${ }^{22}$. At the beginning of the study, case 1 presented frontal DTI-FA values significantly inferior compared to those of case 2 and to the control group. The evaluation 4 years latter showed a slight loss of frontal DTI-FA values in both case 1 and 2, in comparison to the control sample. A loss in the posterior white matter in case 2 was also observed (Table 2).

\section{DISCUSSION}

The evolution of GD may vary significantly ${ }^{6}$, as shown by the illustrative cases. It is believed that in some situations the affective symptoms might be a response to psychological stress $^{23}$. In other cases, however, it can be considered within a spectrum of cognitive and behavioral impairment of vascular etiology, comprising vascular depression and $\mathrm{VMCl}^{9}$. Some studies suggest that these behavioural symptoms may be the earliest signs of $\mathrm{VCl}$ in progress ${ }^{8}$.
It may be difficult to distinguish between cases of depressed patients demonstrating initial signs of VCl and those whose cognition will improve to treatment with antidepressants. Executive function appears to be the most relevant element in patients with GD, and is outstanding manifestation in vascular depression. However, these affective symptoms may represent an important, confounding element in the interpretation of cognitive deficits in non-demented and demented patients ${ }^{24}$. Considering transversal studies, there is agreement about the frequent presence of executive dysfunction in DG ${ }^{25}$. However, results showed variability when considering the specificity of executive deficits associated with depression ${ }^{26-29}$. Thus, long-term follow-up of cases is fundamental in determining diagnosis.

Long-term follow-up permitted the assessment of the cases in the absence and presence of depressive symptoms. This made possible to clarify the role of affective symptoms in each case. The initial cognitive evaluation of case 1, in the absence of depressive symptoms, revealed executive dysfunction (TMT and CLOX, and CAMCOG subscales attention and abstract thinking). The reappearance of depressive symptoms during the third year was accompanied by a global cognitive worsening, as shown by global CAMCOG, and executive function lower scores (attention and abstract thinking, TMT and (LOX). In the last year the patient's depressive symptoms showed improvement. However, global CAMCOG and memory subscale remained low, as well as executive function.

The initial evaluation of case 2 showed high scores regarding depressive symptoms (Table 3) and executive dysfunction (TMT and CLOX) (Table 1), and impairment of attention and abstract thinking. These cognitive parameters improved with the improvement of the depressive symptoms in the long-term.

Both cases presented impaired cognition accompanied by depression. However, the cognitive evolution, as seen above, was different. Case 1, with severe levels of WMH, diagnosed as vascular depression, displayed $\mathrm{MCI}$ (CDR 0.5) with executive dysfunction, worsening over time, evolving towards a more advanced state of VCI (CDR 1). Case 2, with mild levels of WMH and GD, and executive dysfunction, evol- 




Figure 1. Case 1. MRI-FLAIR acquisition of three representative axial sections that show WMH burden. A: $\mathrm{mFazekas} \mathrm{score}=2$; B: mFazekas score $=3$.

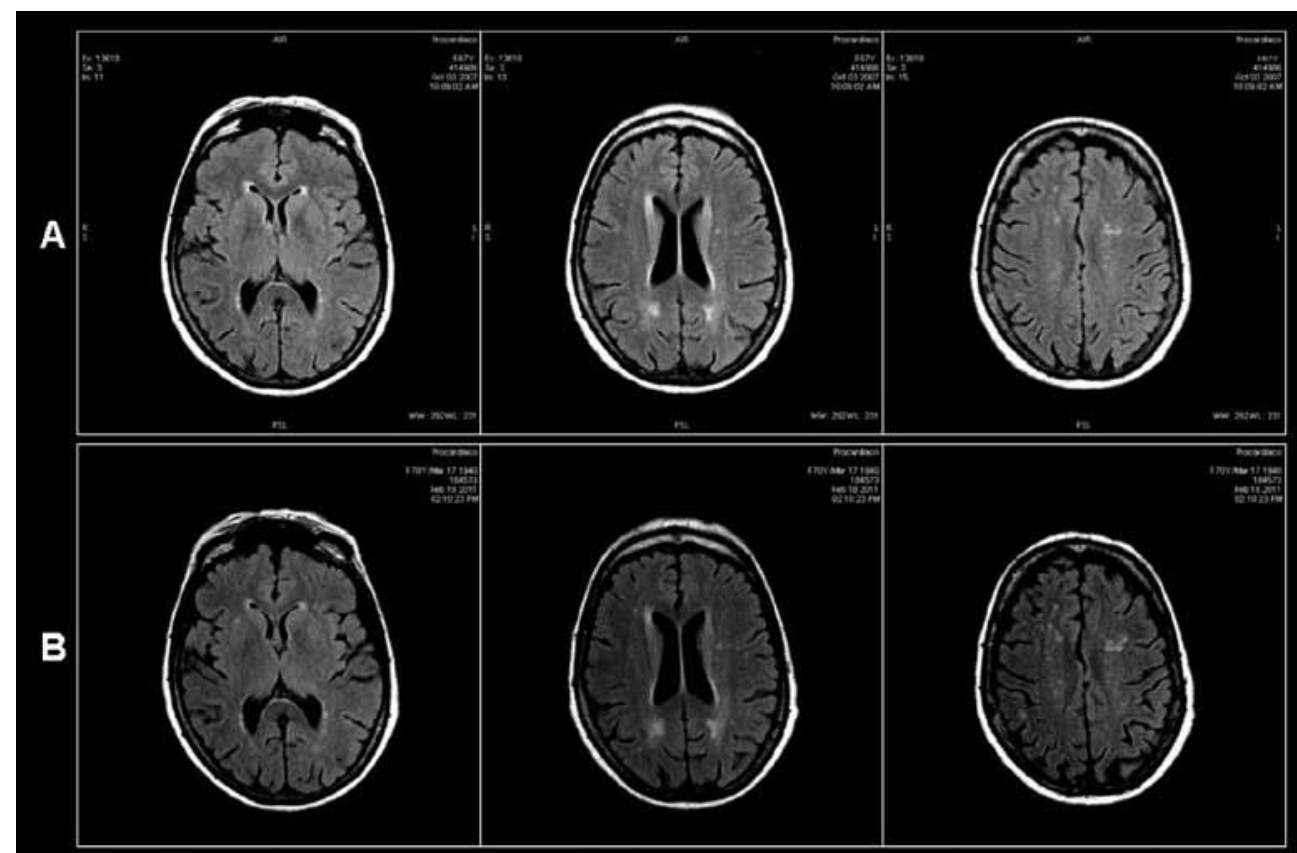

Case 2

Figure 2. Case 2. MRI-FLAIR acquisition of three representative axial sections that show WMH burden. A: $\mathrm{mFazekas} \mathrm{score}=1$; B: $\mathrm{mFazekas} \mathrm{score}=1$.

ved to normalization of cognition (CDR 0). Patients with GD frequently demonstrate executive dysfunction, associated with difficulties in performing instrumental daily-life activities, which may persist even after the successful treatment of mood disorder. These particular patients, may, over time, develop VD ${ }^{6}$
For a better understanding of the relationship between the WMH and axonal integrity of the subcortical white matter, the neuroimaging evaluation was repeated at the end of the follow-up period. The present study shows evidence that a worsening of WMH lesions is associated with a worse prognosis for GD and cognitive decline. However there are few 
studies demonstrating this relation ${ }^{30-32}$ Steffens et al. ${ }^{33}$ described a patient with recurring GD over a 4-year period, which evolved to cognitive decline and $\mathrm{VaD}$. This patient was also screened for the presence of $\mathrm{WMH}$ at the end of the follow-up, which showed worsening of the lesions ${ }^{33}$. Another study showed the same pattern with a two-year follow-up ${ }^{34}$.

The comparison between the baseline and final neuroimaging studies were able to explain different patterns of GD. The lesions may contribute not only to the etiology of the affective symptoms and cognitive impairment in some case of $\mathrm{GD}^{13,35}$, but also to a negative prognosis of the $\operatorname{cases}^{36}$. The DTI-FA values were reduced in the frontal white matter of case 1 , and were in normal range in case 2 , as compared to a normal group, which seems to be the determining factor for the different prognosis in each case. The posterior white matter showed reduced values in case 1, and remained in the normal range in case 2 (Table 2). Reduced DTI-FA values are related to loss of axonal integrity, and taking into account the frontal white mater. It is compatible with disconnection of prefrontal-subcortical circuits, considered the neuroanatomical substrate underlying affective and cognitive manifestations ${ }^{10}$, and appear to have prognostic relevance in $\mathrm{GD}^{14}$. Other studies corroborate these findings, despite some variation ${ }^{37,38}$. The reduction of posterior DTI-FA values in case 1 is possibly related to the interruption of other circuits, not identified in the present study.

The two cases differed with regard to the time needed to show a response to treatment with anti-depressants, which is an important factor in defining the sub-types of elderly depression. Dew et al. ${ }^{39}$ described four groups of patients with $G D$, each with different responses to therapy. The first group showed rapid improvement with the use of antidepressants (the best prognosis), the second, showed improvement, but required a longer period of antidepressant use, the third group demonstrated an oscillating course with improvement, and the fourth group proved to be resistant to treatment (the worst prognosis $)^{39}$. In a recent study Alexopoulos et al..$^{14}$ evaluated 48 elderly depressed individuals (23 with refractory depression and 25 who responded to treatment with antidepressant medication). Just as described by Dew et al., the case 2 of this study had a rapid response to treatment and evolved better, while case 1 showed a poorer response to antidepressant treatment with subsequent cognitive impairment.

\section{CONCLUSION}

The association of vascular factors (including vascular risk factors and WMH load) and GD has guided the development of the VaDp hypotheses and the mechanisms which predispose, initiate or perpetuate this subtype of depression. Neuroimaging studies, especially those with WMH assessment and quantitative DTI-FA have revealed the disruption of pre- frontal-subcortical circuits. These changes might represent a neuroanatomical substrate associated with $\mathrm{VaDp}$ and the accompanying cognitive impairment, as well as influencing the kind of response to antidepressant treatment.

The existence of different subtypes of $G D$, as presented in this report, one with cognitive improvement and the other with cognitive decline, points out the pathophysiological heterogeneity of DG, and suggests a possible continuum $\mathrm{VaDp}$ and $\mathrm{VCl}$ (including $\mathrm{VMCl}$ and $\mathrm{VaD}$ ), with significant impact on case management.

\section{ACKNOWLEDGEMENTS}

To Luzinete Alvarenga, librarian, for organizing the references. My wife Clarisse and my son Felipe for their inspiration and encouragement.

\section{REFERENCES}

1. Panza F, Frisardi V, Capurso C, D'Introno A, Colacicco AM, Imbimbo BP, et al. Late-life depression, mild cognitive impairment, and dementia: possible continuum? Am J Geriatr Psychiatry. 2010;18:98-116.

2. Copeland JR, Beekman AT, Braam AW, Dewey ME, Delespaul P, Fuhrer R, et al. Depression among older people in Europe: the EURODEP studies. World Psychiatry. 2004;3:45-9.

3. Mulsant BH, Ganguli M. Epidemiology and diagnosis of depression in late life. J Clin Psychiatry. 1999;60(Suppl 20):9-15.

4. Andrade LH, Walters EE, Gentil V, Laurenti R. Prevalence of ICD - 10 mental disorder in a catchment area in the city of São Paulo, Brazil. Soc Psychiatry Psychiatr Epidemiol. 2002;37:316-25.

5. Costa E, Barreto SM, Uchoa E, Firmo J0, Lima Costa MF, Prince M. Prevalence of International Classification of diseases, 10th Revision Common Mental Disorders in the elderly in a Brazilian community: the Bambui Health Ageing study. Am I Geriatr Psychiatry. 2007;15:17-27.

6. Bhalla RK, Butters MA, Becker JT, Houck PR, Snitz BE, Lopez OL, et al. Patterns of mild cognitive impairment after treatment of depression in the elderly. Am J Geriatr Psychiatry. 2009;17:308-16

7. Alexopoulos GS, Meyers BS, Young RC, Campbell S, Silbersweig D, Charlson M. The vascular depression hypothesis. Arch Gen Psychiatry. 1997;54:915-22.

8. Baernes E, Alexopoulos G, Lopez 0, Wilhanson J, Yaffe K. Depressive symptoms, vascular disease, and mild cognitive impairment. Arch Gen Psychiatry. 2006;63:273-80.

9. Zimmerman JA, Mast BT, Miles T, Markides KS. Vascular risk and depression in the Hispanic Established Population for the Epidemiologic Study of the Elderly (EPESE). Int I Geriatr Psychiatry. 2009;24:409-16.

10. Tekin S, Cummings JL. Frontal-subcortical neuronal circuits and clinical neuropsychiatry: an update. J Psychosom Res. 2002;53:647-54.

11. Davidson RJ, Lewis DA, Alloy LB, Amaral DG, Bush G, Cohen JD, et al. Neural and behavioral substrates of mood and mood regulation. Biol Psychiatry. 2002;52:478-502.

12. Drevets WC. Geriatric depression: brain imaging correlates and pharmacologic considerations. J Clin Psychiatry. 1994;55(Suppl A):71-81.

13. Taylor WD, MacFall JR, Payne ME, McQuoid DR, Steffens DC, Provenzale JM, et al. Greater MRI lesion volumes in elderly depressed subjects than in control subjects. Psychiatry Res. 2005;139:1-7.

14. Alexopoulos GS, Murphy CF, Gunning-Dixon FM, Latoussakis V, Kanellopoulos D, Klimstra $S$, et al. Microstructural white matter abnormalities and remission of geriatric depression. Am J Psychiatry. 2008;165:238-44.

15. Alexopoulos GS, Kiosses DN, Choi SJ, Murphy CF, Lim KO. Frontal white matter microstructure and treatment response of late-life depression: a preliminary study. Am J Psychiatry. 2002;159:1929-32. 
16. Moreno RA, Moreno DH. Escalas de depressão de Montgomery \& Asberg (MADRS) e de Hamilton (HAM-D). Rev Psiq Clín. 1998;25:262-72.

17. Camozzato AL, Kochhann R, Simeoni C, Konrath CA, Pedro Franz A, arvalho A, et al. Reability of Brazilian Portuguese version of the neuropsychiatric inventory (NPI) for patients with Alzheimer's disease and their caregivers. Int Psychogeriatr. 2008;20:383-93.

18. Engelhardt E, Tocquer C, Charles A, Moreira DM, Okamoto IH, Cavalcanti JLS. Demência vascular: critérios diagnósticos e exames complementares Dement Neuropsychol. 2011;5(Supp11):49-77.

19. Bueno D. Perfil de idosos com demência e depressão: status cognitivo medido pelo CAMCOG, escolaridade e histórico das habilidades sociocognitivas Campinas, SP. 2009 [s.n.]: Dissertação (Mestrado) Universidade Estadual de Campinas. Faculdade de Ciências Médicas.

20. Gouw AA, van der Flier WM, van Straaten EC, Pantoni L, Bastos-Leite AJ, Inzitari D, et al. LADIS study group. Reliability and sensitivity of visual scales versus volumetry for evaluating white matter hyperintensity progression. Cerebrovasc Dis. 2008:25(3):247-53.

21. de Leon MJ, Golomb J, George AE, Convit A, Tarshish CY, McRae T, et al. The radiologic prediction of Alzheimer disease: the atrophic hippocampal formation. AJNR. Am J Neuroradiol. 1993;14(4):897-906.

22. Engelhardt E, Moreira DM, Laks J. The brain subcortical white matter and aging. A quantitative fractional anisotropy analysis. Dement Neuropsychol. 2009;3:228-33.

23. Anstey KJ, Burns R, Butterworth P, Windsor TD, Christensen H, Sachdev P. Cardiovascular risk factors and life events as antecedents of depressive symptoms in middle and early-old age: PATH Through Life Study. Psychosom Med. 2009;71:937-43.

24. Wright SL, Persad C. Distinguishing between depression and dementia in older persons: neuropsychological and neuropathological correlates. J Geriatr Psychiatry Neurol. 2007;20:189-98.

25. Roman G. Vascular depression: an archetypal neuropsychiatric disorder. Biol Psychiatry. 2006;60:1306-8.

26. Kramer-Ginsberg E, Greenwald B, Krishnan R, Christiansen B, Hu J, Ashtari M, et al. Neuropsychological functioning and MRI signal hyperintensities in geriatric depression. Am J Psychiatry. 1999;156:438-44.

27. Hart RP, Kwentus JA. Psychomotor slowing and subcortical-type dysfunction in depression. J Neurol Neurosurg Psychiatry. 1987;50:1263-6.
28. Boone KB, Lesser IM, Miller BL, Bruce L, Wohl M, Berman N, et al. Cognitive functioning in older depressed outpatients: relationship of presence and severity of depression to neuropsychological tests cores. Neuropsychology. 1995;9:390-8.

29. Butters M, Whyte E, Nebes R, Begley AE, Dew MA, Mulsant BH, et al. The nature and determinants of neuropsychological functioning in late-life depression. Arch Gen Psychiatry. 2004;61:587-95

30. Steffens DC, Potter GG, MCQuoid DR, MacFall JR, Payne ME, Burke JR, et al. Longitudinal resonance imaging vascular changes, apolipoprotein E genotype, and development of dementia in the neurocognitive autcomes of depression in the elderly study. Am I Geriatr Psychiatry. 2007;15:839-49.

31. Taylor WD, Steffens DC, Macfall JR, McQuoid DR, Payne ME, Provenzale JM, et al. White matter hyperintensity progression and late-life depression outcomes. Arch Gen Psyshiatry. 2003;60:1090-6.

32. Nebes RD, Reynolds CF, Boada F, Meltzer CC, Fukui MB, Saxton J, et al. Loongitudinal increase in the volume of white matter hyperintensities in late-onset depression. Int I Getriatr Psychiatry. 2002;17:526-30.

33. Steffens DC, Taylor WD, Krishnan R. Progression of subcortical ischemic disease from vascular depression to vascular dementia. Am J Psychiatry. 2003;160:1751-6.

34. Loganathan S, Phutane VH, Prakash 0 , Varghese M. Progression of vascular depression to possible vascular dementia. J Neuropsychiatry Clin Neurosci. 2010;22:451.

35. Thomas AJ, O'Brien JT, Davis S, Ballard C, Barber R, Kalaria RN, et al. Ischemic basis for deep white matter hyperintensities in major depression: a neuropathological study. Arch Gen Psychiatry. 2002;59:785-92.

36. Sheline YI, Pieper CF, Barch DM, Welsh-Bohmer K, McKinstry RC, MacFall JR, et al. Support for the vascular depression hypothesis in late-life depression: results of a 2-site, prospective, antidepressant treatment trial. Arch Gen Psychiatry. 2010;67:277-85.

37. Nobuhara K, Okugawa G, Sugimoto T, Minami T, Tamagaki C, Takase K, et al. Frontal white matter anisotropy and symptom severity of late-life depression: a magnetic resonance diffusion tensor imaging study. J Neurol Neurosurg Psychiatry. 2006;77:120-2.

38. Yang $Q$, Huang $X$, Hong N, Yu X. White matter microstructural abnormalities in late-life depression. Int Psychogeriatr. 2007;19:757-66.

39. Dew MA, Reynolds CF, Mulsant B, Frank E, Houck PR, Mazumdar S, et al. Initial recovery patterns may predict which maintenance therapies for depression will keep older adults well. J Affect Disord. 2001;65:155-66. 